\title{
Sorting through the garbage can: under what conditions do governments adopt policy programs?
}

\author{
Fritz Sager • Yvan Rielle
}

Published online: 16 September 2012

(C) Springer Science+Business Media, LLC. 2012

\begin{abstract}
The paper aims at explaining the adoption of policy programs. We use the garbage can model of organizational choice as our theoretical framework and complement it with the institutional setting of administrative decision-making in order to understand the complex causation of policy program adoption. Institutions distribute decision power by rules and routines and coin actor identities and their interpretations of situations. We therefore expect institutions to play a role when a policy window opens. We explore the configurative explanations for program adoption in a systematic comparison of the adoption of new alcohol policy programs in the Swiss cantons employing Qualitative Comparative Analysis. The most important conditions are the organizational elements of the administrative structure decisive for the coupling of the streams. The results imply that classic bureaucratic structures are better suited to put policies into practice than limited government.
\end{abstract}

Keywords Program adoption - Garbage can model · Crisp set qualitative comparative analysis (csQCA) · Alcohol policy · Swiss cantons

\section{The adoption of policy programs as research gap}

This paper aims at explaining the adoption of policy programs. Policy programs have become a major form of public intervention in the post war area. However, while there is a vast interest in political science in both policy change (e.g., Hall 1993; Sabatier and Jenkins-Smith 1999) and policy instrument choice (e.g., Bemelmans-Videc et al. 1998),

\footnotetext{
F. Sager $(\bowtie)$

Center of Competence for Public Management, University of Bern, Schanzeneckstrasse 1, P.O. Box 8573, 3001 Bern, Switzerland

e-mail: fritz.sager@kpm.unibe.ch

Y. Rielle

polsan GmbH-Büro für Politikanalyse und-beratung, Effingerstrasse 54, Postfach 6052, 3001 Bern, Switzerland e-mail: yvan.rielle@polsan.ch
} 
comparatively little and rather scattered work has been done on the action level between the two, that is, policy programs (e.g., Feiock and West 1993; Matishoff 2008). With the present paper, we want to contribute to filling this research gap by taking the adoption of alcohol policy programs in the Swiss cantons, that is, the middle federal rung in the Swiss state structure, as an example.

In the following, we state three main arguments: first that the rather diffuse knowledge on the causes of program adoption is due to the fact that it is an administrative rather than a political decision whether to adopt a policy program or not; second that the garbage can model of organizational choice makes an adequate theoretical framework for the explanation of program adoption if complemented with institutionalist theory and that it is particularly suited for the field of alcohol policy with its marked ambiguity due to its different framings; and third that the approach of Qualitative Comparative Analysis (QCA) enables us to investigate the interaction between the streams of the garbage can model thanks to its ability to deal with complex causation.

In the next section, we will conceptualize the phenomenon to be explained, namely the adoption of alcohol policy programs. Subsequently, we will complement the garbage can model with neo-institutionalism and derive nine conditions in order to explain the cantonal diversity observed in alcohol prevention program adoption before we will briefly discuss our research design and method, namely a crisp set qualitative comparative analysis (csQCA). By taking advantage of two surveys of the relevant decision-making and implementing bodies of Swiss alcohol policy at the subnational level, we are able to compare alcohol program adoption in each canton between 1999 and 2004. We present these data before turning to the results of the analysis in the subsequent part. The findings will be discussed in light of our theory in the section that follows. The final section will summarize the main findings and derive conclusions with regard to program adoption as well as to theoretical implications.

\section{The phenomenon to be explained: the adoption of new alcohol policy programs}

A classic definition of policy programs is provided by Pressman and Wildavsky (1974: $\mathrm{xiv}-\mathrm{xv}$ ) who distinguish program from policy as follows: "Let us agree to talk about policy as a hypothesis containing initial conditions and predicted consequences. (...) A program consists of governmental action initiated in order to secure objectives whose attainment is problematical. A program exists when the initial conditions - the 'if' stage of the policy hypothesis-have been met. The word 'program' signifies the conversion of a hypothesis into governmental action. (...) Considered as a whole, a program can be conceived of as a system in which each element is dependent on the other." Hall (1993: 278) sees policy change as the "deliberate attempt to adjust the goals or techniques of policy in response to past experience and new information." While policy change thus involves modification of the policy hypothesis including problem perception and the value-based choice of solutions, the program decision is located at a subordinate level in that it regards the decision to become operative in a coherent manner. A program consists of different policy instruments the choice of which again is value-laden as argue Schneider and Ingram (1993). As a consequence, we see the policy program adoption as a primarily executive-administrative decision as opposed to policy change and instrument choice, which imply much more political debate.

We investigate the causes for program adoption with the case of alcohol control policy program adoption in the Swiss member-states. We do so for two main reasons: first, policy 
programs are an especially common form of intervention in the field of public health. However, as stated above in general, also with regard to public health and alcohol policy in particular, research so far was interested in policy change (Baumberg and Anderson 2008; Ugland 2003) and instrument choice (Meier 1994; Sager 2009), but not in program adoption. Second, Switzerland is highly federalistic and decentralized, with the main competences for public policies held at the sub-national level of the cantons. Accordingly, the field of alcohol prevention policy is regulated in a particularly inconsistent manner, since the cantons are equipped with very extensive programming and implementation competences, leading to a pronounced heterogeneity and variance in cantonal prevention efforts (Sager 2007, 2009).

The time between 1999 and 2004 is considered an appropriate study period because in 1999, the Federal Commission for alcohol-related questions (an external expert commission consulting the Federal Government) started an initiative to promote cantonal alcohol policy programs. Whereas the commission had drafted a National Alcohol Action Plan consisting of a number of measures, there were no specific instruments promoted for the cantonal level. The aim of this initiative was not to install a given set of policy measures, but to launch a bottom-up process with cantons starting their own alcohol policy programs. Thus, all 26 cantons have been exposed to the same vertical stimulus. However, the decision to develop a program was left to the cantonal authorities as there was no coercive power the commission could have exerted. Correspondingly, the ways in which the cantons responded to this impulse vary greatly. While some cantons developed new programs from the scratch, others did not even change their existing instruments. This extremely heterogeneous pattern offers an outstanding opportunity for the comparative analysis of situational preconditions for program adoption.

The cantonal alcohol policies were assessed in case studies (Sager and Schläpfer 2004) that show which cantons adopted new policy programs between 1999 and 2004 or looked into the introduction of coherent, integrated overall alcohol policy programs. The outcome "program adoption" (PROGADOPT) is coded dichotomously $(1=$ change, $0=$ no change) as required for the method we use. In total, we find adoption of alcohol policy programs in ten cantons, while sixteen cantons have not changed their activities in the research period. The respective data on the cantons are presented in the last column in Table 2.

In the next section, we present our theoretical framework based on the garbage can model and neo-institutionalism from which conditions for our analysis will be derived.

\section{The garbage can model and institutionalism: conditions for program adoption}

For our analysis, we need a scheme that is adequate for both our subject "program adoption" and our empirical test case "alcohol policy". We believe the garbage can model of organizational choice (Cohen et al. 1972) to fit this shoe for two reasons: first, we consider program adoption an administrative rather than a political decision, and accordingly, we need an organizational theory of decision-making rather than a political theory. Second, alcohol policy is a field of great ambiguity as it can be framed in different ways from trade and EU integration policy to agricultural policy to health and social policy (Ugland 2003). The garbage can model was developed to deal with decision-making in situations with problematic preferences as can be constituted by competing frames. Correspondingly, we consider the garbage can model a theoretical framework at the adequate analytical level of organizations and matching the characteristics of our test case. 
The concept has made an impressive career in the study of decision-making not least due to its adaption to public policy analysis by Kingdon (1984) and has not lost its popularity to date (e.g., Nowak 2010). The main innovation of the model lies in its "attempt to push organizational decision theory into the previously uncharted territory of 'organized anarchies"' (Padgett 1980: 583). Cohen et al. (1972) rejected a linear logic of rational decision-making through a line of subsequent stages and proposed an alternative view of a conjunction of different streams at a given time. As a consequence, "solutions may be linked to problems more by chance than design" (Bendor et al. 2001: 188). There are different applications of the garbage can model and the different streams are not labelled consistently in these models. This variance of models is well in line with the inventors' spirit which "has always been to encourage colleagues to play with the basic ideas, rather than defend them endlessly" (Olsen 2001: 192). In the following, we intend to comply with Olsen's invitation.

As Olsen (2001: 193) states, "the pure garbage can model is basically institution free, or structure is treated as exogenous." This lack of institutions in the model has been identified as a problem by various critics. Padgett (1980: 583, also Bendor et al. 2001: 173) questions the structural underpinning of the model: "Garbage can processes seem curiously divorced from the familiar structural phenomena of organizational differentiation, centralization policy, and standard operating procedures of traditional concern to classical organization theorists." Two arguments are put forward as to why institutions are a sensible amendment to the garbage can model. First, Padgett (1980: 583) states that the "relative lack of emphasis on "the stable, the routine, and the channeling effects that rules have on behavior' (Perrow 1977) encourages the misperception that the organized anachy paradigm can be usefully applied only to highly decoupled and unorthodox organizational systems." Second, Heimer and Stinchcombe (1999: 26) argue "that the identities, histories, and institutional meanings of items in the decision streams are central to the methodology and the empirical use of the garbage can model." While the first argument stems from classic organization theory, the second directly relates to later works by March and Olsen (1984, 1989, Olsen 2006). In these writings, they develop new institutionalism (NI) as "an attempt to supplement ideas of consequential action, exogenous preferences, garbage cans, and inefficient histories ... NI also represents a shift in focus from the logic of consequences ... to alternative forms of intelligence and behavioral logics. In particular, it explores a logic of appropriateness based on a sense of identity (March and Olsen 1989, 23).... Actors behave in accordance with their interpretation of rules and practices that are socially constructed, publicly known, anticipated, and accepted" (Olsen 2001: 193). Particularly because we are interested in decision within public administration as the "preeminent institutional form in modern society" (Zucker 1983: 1), we share this view and therefore adopt a neo-institutionalist stance in our analysis.

As for both the policy stream and the policy window, we consider them stable in our test case. Kingdon (1984: 173) uses the term policy window for the momentary "opportunity for advocates of proposals to push their pet solution, or to push attention to their special problems." The Federal Commission's initiative to promote cantonal alcohol policy programs can be understood as such an opportunity for cantonal actors that was open during the time span under study. Likewise, the commission's proposal of a "National Alcohol Action Plan" is considered here as the policy solution looking for a problem. We thus face a common vertical stimulus from the federal level in all cantons, but program adoption only takes place in half of them. We assume that this is due to the specific settings of politics, problems and structure the vertical stimulus found in the cantons. Correspondingly, we consider the streams of politics and problems and complement them with their institutional setting. 
As Varone et al. (2006), we will not focus on singular explanations, but on the settings of conditions for program adoption. We therefore use the theory to identify relevant conditions. What we are interested in is how these conditions interact in constellations. Based on theoretical positions put forward in comparative research on alcohol policy (Meier 1994; Sager 2007, 2009), we will identify nine situational conditions expected to make a difference to policy program adoption.

Political stream: conditions at the politics level

We consider two conditions at the politics level relevant for policy program adoption:

\section{First condition: Party political staffing of the key department for alcohol policy}

According to Meier (1994: 179-180), the strength of the major party makes a significant difference in alcohol policy. The "partisan theory" (Hibbs 1977) attributes particular importance to the party-political composition of parliament and government when explaining differing political results. Comparative welfare state research emphasizes the importance of a strong left-wing, which also has an effect in health policy. With their support for a strong (social) state, the political left also has a more positive stance with regard to active health-oriented alcohol policy than do liberal forces. It follows that the greater the influence of the political left-wing on the health policy of a canton is, the more favorable are the conditions for alcohol policy program adoption. The party-political staffing of the key department for alcohol policy can be expected to be decisive in this.

\section{Second condition: veto players and promotors}

The veto players theory put forward by Tsebelis (2002) assumes that with an increasing number of institutions necessary for a political decision ("veto points"), the decisionmakers' room for maneuver decreases and the chances for implementing political reforms dwindle. Direct democracy instruments have influenced federal and cantonal decisionmaking processes in Switzerland by acting as veto points. They led either to veto players' positions being anticipated or to the actors being involved in the decision-making process at an early stage and with strong veto powers. It is difficult to implement an active healthoriented alcohol policy, which intends to move away from the status quo by means of coherent overall programs, if powerful actors threaten to exercise their veto or such threat is to be expected on the basis of past experience. The economic importance of the alcohol industry can thus limit the scope of cantonal alcohol policy by acting as a veto player. While Tsebelis' (2002) veto points are an institutionalist concept, we consider veto players as part of the politics stream. The main reason is that we focus on the political strength of actors in terms of power resources rather than on the formal veto points which in the case of direct democracy are the same for all actors in a jurisdiction. The second reason lies with Kingdon's (1984: 188) concept of political entrepreneurs whom he describes "as advocates who are willing to invest their resources - time, energy, reputation, money-to promote a position in return for anticipated future gain in the form of material, purposive, or solidary benefits. ... The entrepreneurs are found in many locations. No single formal position or even informal place in the political system has a monopoly for them." Kingdon (1984) considers the policy entrepreneurs crucial for the coupling of streams when a policy window opens. In the empirical context of our study, however, we could not find evidence 
for such a decisive role of single actors. Rather, we found promoters of active alcohol policy that played a role which can be described as the counterpart to veto players: whereas the latter use their resources to hamper active alcohol programs, the former employ the same strategies to advance them. Correspondingly, we decided to take the two sides of policy advocacy together with the condition PROMVETO operationalized as the presence of strong promoters AND weak or no veto players.

\section{Problem stream}

The handling of societal problems in the garbage can model diametrically contradicts the rational logic of socio-economic theories seeing state functions as a reaction to social and economic developments and the functional problems of state polities stemming from these. As opposed to this view, the garbage can model claims that "people do not set about to solve problems here. More often solutions search for problems. People work on problems only when a particular combination of problem, solutions, and participants in a choice situation makes it possible" (Kingdon 1984: 91). A systematic link between problem situation and alcohol program adoption would question the assumption of independent streams. As our test case regards preventive alcohol policy, we refer to comparative health policy analysis focusing on the prevalence of the problem at issue (Vatter and Rüefli 2003).

\section{Third condition: alcohol consumption}

The problems addressed by alcohol programs are not alcohol consumption as such but its consequences, that is, alcohol-related social harm such as violence or estrepement and the burden of disease caused by riskful drinking. While there are epistemological statistics on these problems, these data do not cover the Swiss cantons. Official health statistics for the cantons address drinking behavior only in a very general manner, for example, per capita consumption of alcohol. We decide to take the proportion of people per canton who consume alcohol more than once a day as best indicator at hand for alcohol-related problems. In Rehm et al.'s (1999: 219) comparison of three methods for assessing alcohol consumption, the graduated frequency measure to which our indicator corresponds consistently yielded higher estimates of the prevalences of high risk drinking and harm. As for social costs, Jeanrenaud (2003) estimates a total amount of 6.7 billion Swiss franks per year, that is, 1,000 franks per capita due to alcohol abuse. As for the burden of disease, Rehm et al. (2003: 1209) find the average volume of alcohol consumption "to increase risk for the following major chronic diseases: mouth and oropharyngeal cancer; oesophageal cancer; liver cancer; breast cancer; unipolar major depression; epilepsy; alcohol use disorders; hypertensive disease; hemorrhagic stroke; and cirrhosis of the liver." Hence, while we do not expect program adoption in a canton to be justified with the respective proportion of people who consume alcohol more than once a day, we argue that the variable can serve as a valid proxy for the alcohol-related problems such programs address.

Institutional setting: conditions at the level of organizational structure

As developed above, we argue that the coupling of streams may depend on institutions. Institutions distribute decision power by rules and routines and coin actor identities and their interpretations of situations. We therefore expect institutions to play a decisive role when a policy window opens. In our analysis of the institutional setting, we follow Lodge 
(2003: 163, also Olsen 2006): "One of the basic tenets of the statist and historical institutional literature has been its emphasis on the internal organization of the state, particularly the political-administrative nexus. Administrative capacities are said to influence the scope of 'bounded innovation' in policy reform." We consider the following six organizational structural characteristics:

\section{Fourth condition: degree of centralization}

Centralization, taken as "the degree to which power and control in a system are concentrated in the hands of relatively few individuals" (Rogers 1995: 380), basically considers the actual inner organization of the relevant bureaucratic bodies. Whereas in some cantons, alcohol prevention is concentrated in one unit, others entertain operative satellites or split prevention tasks among various administrative units. Program adoption can be expected if the alcohol policy administrative structures are centralized as the room for maneuver is larger and it will be easier to develop coherent action (Sager 2007).

\section{Fifth condition: degree of outsourcing of tasks}

Centralization in the above definition also regards the degree to which tasks are outsourced to non-public actors. The outsourcing of tasks leads to the fragmentation of responsibility for a policy and therefore can be expected to hinder the development of coherent and encompassing policy programs. As Cattacin and Lucas (1999) have shown, alcohol policy in Switzerland is particularly marked by non-state actors. We expect the adoption of a cantonal alcohol policy program if the bulk of the tasks are not outsourced to third parties.

\section{Sixth condition: professional specialization}

A further issue is whether policy-making is strongly influenced by the degree of professional specialization and differentiation in the responsible administrative bodies (Sager 2007). Professionalism describes the degree "to which an organization's members possess a relatively high level of knowledge and expertise, usually measured by the member's range of occupational specialties and their degree of professionalism expressed by formal training" (Rogers 1995: 380). Correspondingly, we expect program adoption if there is a professionally staffed administrative body specially entrusted with the policy.

\section{Seventh condition: coordination}

From an organizational perspective, we must also consider the management of the actual policy formulation and implementation processes. O'Toole and Meier (1999) show managerial activities to be substantive contributors to organizational success. In this respect, there are two strategies expected to have an impact on alcohol policy design decisions (Sager 2003), namely coordination and cooperation. Firstly, the coordination among the agencies concerned within a cantonal public administration fosters mutual learning and can thus contribute to innovation (Sager 2005). Consequently, program adoption can be expected in cantons with a high level of inner administrative coordination. 


\section{Eighth condition: number of departments involved}

Coordination also is a matter of the number of agents who coordinate. A high number of relevant agents leads to fragmentation of responsibility and complicates coordination (Kaufmann and Sager 2006). This effect can be expected to be even stronger if the respective units are equipped with decision power as it is the case for executive departments (Sager 2009). Fragmentation thus differs from inner administrative centralization in that it regards the level of political departments under the control of the respective members of the cantonal executive. This adds executive politics as well as differing policy cultures to the analysis. Heads of departments may disagree on policy for ideological reasons and so may departmental units for epistemological reasons. For example, the transportation department may have different priorities than the health services, and police may disagree with the social services. For both reasons, we expect fragmentation to hinder program adoption. We therefore include the number of involved executive departments as eighth condition in our analysis.

\section{Ninth condition: vertical and horizontal cooperation}

As said above, we also expect cooperation to foster program adoption. On the one hand, horizontal inter-cantonal cooperation can lead to learning processes resulting in the adoption of policy programs that have been successful in other cantons. Policy diffusion primarily facilitates innovation. On the other hand, there are also vertical contacts between cantonal and federal authorities. As cantonal administrations often lack the knowledge and expertise necessary for evidence-based policy making, we can also expect strong vertical cooperation to lead to innovation (Sager 2003, 2009). We capture the willingness to cooperate with the variable "Cooperation" which encompasses the two forms of cooperation.

In the garbage can model, it is assumed that the random intersection of the independent streams generates decisions. However, the model does not provide assumptions as to how the streams interact (Zahariadis 2007: 84) which is why we do not formulate configurative hypotheses. Still, we aim to shed light on this interaction, which has methodological consequences as complex causation is implied. We consider the approach of Qualitative Comparative Analysis (QCA), the most appropriate way to tackle this problem. QCA denotes a family of logical methods of case comparison that focus on constellations of factors instead of examining each variable independently (Schneider and Wagemann 2012). Causal complexity is fundamental to QCA: "What makes a certain feature (...) causally relevant in one setting and not in another is the fact that its causal significance is altered by the presence of other features (that is, its effect is altered by context). Similarly, apparently different features can have the same effect depending on which other features they are associated with. (...) This is a primary justification for examining cases as wholes and for trying to decipher how different causal factors fit together" (Ragin 1987: 49). The research design is presented in the next section.

\section{Research design and data}

Our approach is a systematic comparison of cantonal decision-making and implementation structures in the field of alcohol control policy. Switzerland represents an ideal field of investigation for systematic-comparative enquiries into the conditions for the emergence 
and means of functioning of different forms of authority and administrative organization due to its 26 relatively autonomous cantons, which also vary greatly in terms of their contextual features and internal administrative organization. A further advantage of such a cross-sectional analysis is the fact that the superordinate context in terms of the political system of the federal state remains constant for all the objects of enquiry, that is, the cantons. The Swiss cantons are fully-fledged political systems within the common institutional framework of the Swiss nation state.

To address our subject under exploration, we relied upon survey research to generate a comprehensive picture of cantonal alcohol policy activities. Empirically, thus, the paper draws from two large surveys of the Swiss cantons conducted in 1999 and 2004. While the first survey in 1999 was financed as basic research, the second in 2004 was commissioned by two alcohol policy-related federal agencies with a view to developing a federal alcohol policy. In the first empirical investigation in 1999 (Sager and Vatter 2000), a standardized questionnaire was used to ask the relevant decision-making and implementation bodies in the Swiss cantons for information regarding the contents and organization of alcohol prevention and control policy. In the second survey in 2004 (Sager and Schläpfer 2004), personal interviews with cantonal stakeholders and decision-makers were used to obtain information. The questions were the same as in the first survey, so the information gathered consisted of a dataset comparable to the first one. In addition to the original data collected via surveys, the findings have been supplemented by comprehensive case reviews. The personal interviews were accompanied by extensive document analyses of both public and non-governmental records in order to permit reliable case studies to be made for each canton. Table 1 offers an overview over the condition and outcome variables and the way we dichotomized them.

The dichotomization of the variables is due to our choice of method and for most variables based on the obvious presence or absence of a condition. In three cases, we had to set a cutoff point in a continuum: as for the problem condition, it corresponds to a natural break in the data, and as for outsourcing and involved departments, it is based on substantive case knowledge as proposed by Yamasaki and Rihoux (2009: 130). The respective information is presented in Table 1. Table 2 displays the resulting truth table for our analysis.

Program adoption has been observed in ten cantons. As for the derived antecedents, we encounter very heterogeneous patterns. In six cantons, the key department is held by the left-wing party. Only in four cantons, we encounter both strong promoters of a healthoriented alcohol policy and weak veto players, while in twelve cantons, the problem pressure is given according to our definition. The majority of the cantons has decentralized structures $(n=17)$ and outsources most of the alcohol policy tasks $(n=17)$. These two groups of 17 cantons are not identical, though. Specialization is high in eleven cantons. Close coordination within the administration takes place in only six cantons; and in 16 cantons, three or more departments are involved in alcohol policy. Eight cantons display a cooperative strategy in both formulation and implementation of their alcohol policy. Apart from four cases, each case displays a unique configuration. The two cantons of Solothurn and Schaffhausen display the same configuration with the same outcome, while the two cantons of Lucerne and Glarus are contradictory cases, that is, they converge with the conditions, but differ in the outcome. ${ }^{1}$

\footnotetext{
${ }^{1}$ For the analysis, we assigned the contradictory combination to outcome 0 as that was theoretically more plausible (Yamasaki and Rihoux 2009: 132-135), i.e. we included Glarus and excluded Lucerne in the analysis. Before doing so, we aimed to find ways to lift these contradictions by going back to the cases. Due to the limited information, however, this strategy was not successful.
} 


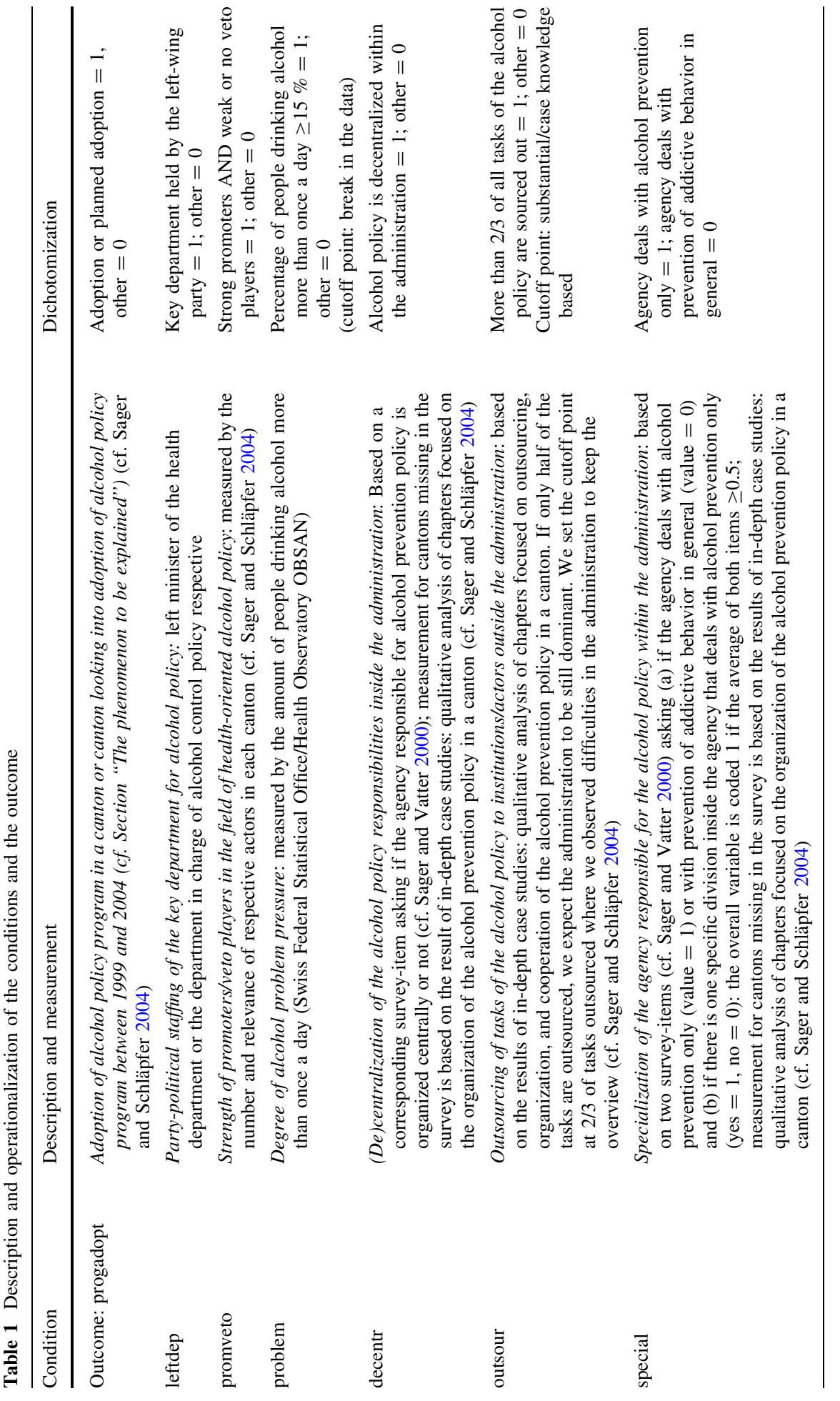




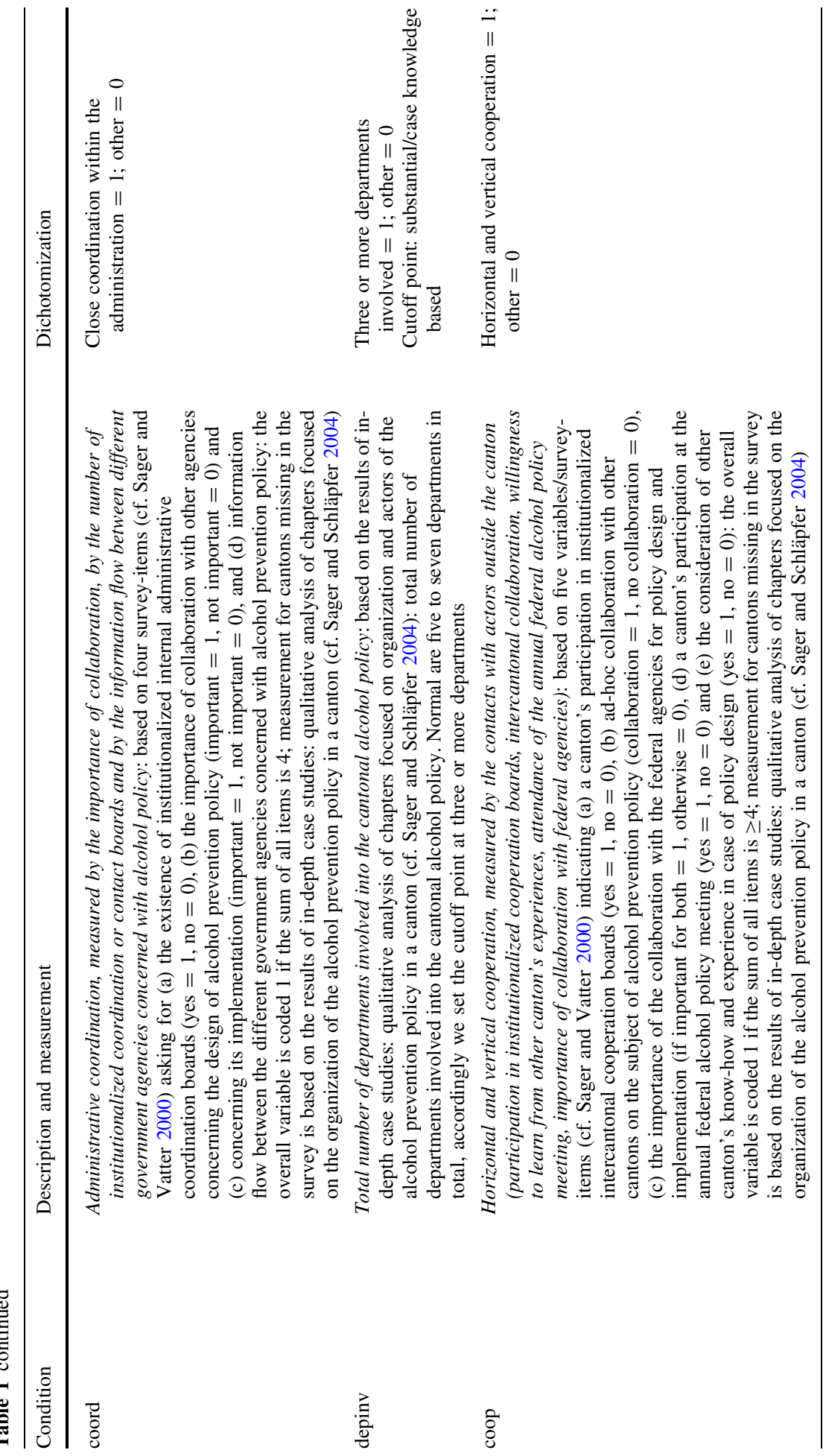




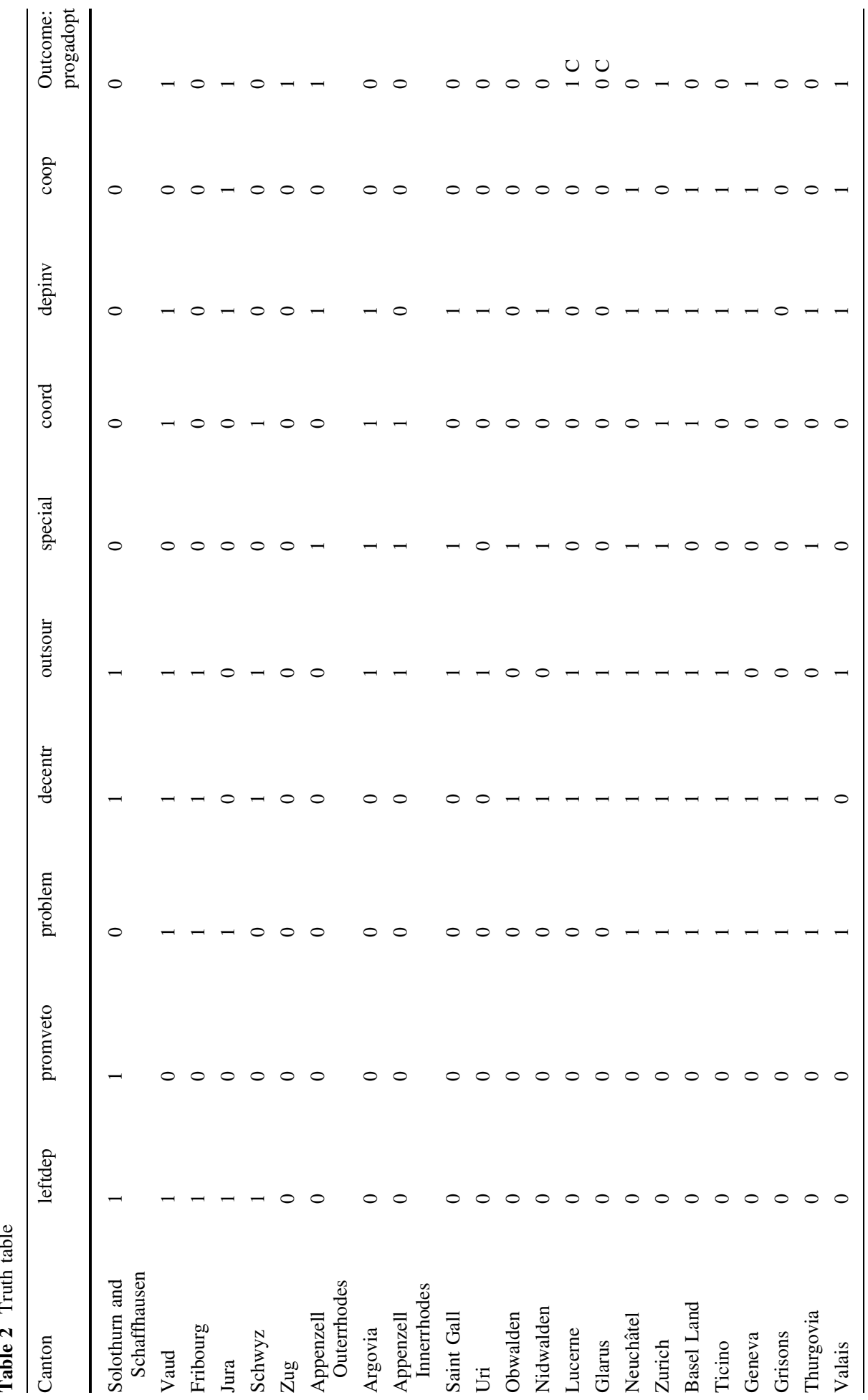




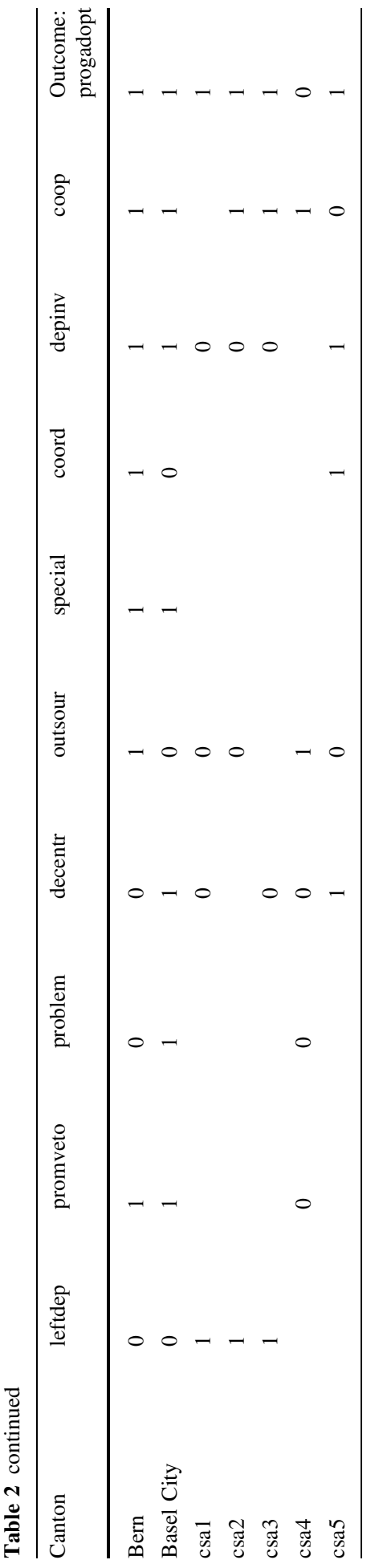


For the empirical analysis, we employ a csQCA as developed by Ragin (1987). The method is based on Boolean algebra, that is, the logic of the binary system with the two logical operators "or" and "and". csQCA displays the coded cases in "truth tables" and converts the different constellations into formulae, which can then be minimized to the most parsimonious explanation of an outcome. The following notation is used in these formulae: "+" represents the logic operator "or", “*” the logic operator "and", upper case letters are used when a variable takes on the value 1 , and lower case letters are used for 0 . The basic idea is that if an outcome $\mathrm{D}$ is found in a case displaying $\mathrm{A}, \mathrm{B}$, and $\mathrm{C}$ as well as in another case displaying $\mathrm{A}$ and $\mathrm{C}$, but not $\mathrm{B}$, it obviously does not make a difference for the occurrence of $\mathrm{D}$ whether $\mathrm{B}$ is present or not. The respective formula is: $\mathrm{A} * \mathrm{~B} * \mathrm{C}+\mathrm{A} * \mathrm{~b} * \mathrm{C} \rightarrow \mathrm{D}$ which accordingly can be minimized to $\mathrm{A} * \mathrm{C} \rightarrow \mathrm{D}$. One case can display different constellations of conditions, which are all treated as equally important. It is such different constellations of conditions, that is, the causal complexity behind a given phenomenon, that are at the core interest in csQCA. The notion of multiple conjunctural causation is crucial in this respect. "[M]ultiple conjunctural causation contains the notion of equifinality, which simply means that different paths can lead to the same outcome" (Berg-Schlosser et al. 2009: 8). Complex causality includes also the notion of asymmetric causal relationships, that is, if the presence of a feature can explain an outcome, its absence does not necessarily imply the opposite outcome. Accordingly, we will analyze both occurrence and non-occurrence of program adoption.

We used the Tosmana (Version 1.3.2)-software for our calculations (based on the Quine-McCluskey-minimization-algorithm) in which we included logical remainders, that is, the respective computer-generated simplifying assumptions were allowed. With 9 conditions, there are $2^{9}$, that is, 512 theoretically possible combinations. We therefore have a "limited diversity"-problem with only 26 cases. However, we use QCA not to test theory, but to develop new theoretical arguments. Berg-Schlosser et al. (2009: 16) state, "QCA does not yield new theories. What it may do, once performed, is to help the researcher generate some new insights, which may then be taken as a basis for a further theoretical development or for reexamination of existing theories." This is the aim of our paper and the inclusion of logical remainders supports this objective. In order to avoid contradictory simplifying assumptions (CSAs) in our remainders, we closely followed Yamasaki and Rihoux (2009: 136-137). We detected five CSAs with the intersection function with the Tosmana software, assigned each with a theoretically plausible outcome value and integrated them as additional cases in the truth table before running Tosmana. The addition of these five cases has not generated any other CSAs.

\section{Results}

The coded cases presented in table 2 form the basis for csQCA. In the following, these data are translated into multiplicative and additive formulae. We use the same notation as in the example presented above. In the following, we will explain both the presence and the absence of policy change. csQCA yields the following solutions for the two situations.

Conditional settings for the program adoption

When including all nine conditions (LEFTDEP + PROMVETO + PROBLEM + DECENTR + OUTSOU + SPECIAL + COORD + DEPINV + COOP), csQCA identifies five combinations of conditions which favor alcohol policy program adoption. 


\begin{tabular}{|c|c|c|}
\hline PROGADOPT: & Program adoption is encountered in cantons & Cases \\
\hline decentral*outsourc & $\begin{array}{l}\text { with a centralized responsibility for alcohol } \\
\text { policy within the administration and where } \\
\text { alcohol policy tasks are not outsourced }\end{array}$ & $\begin{array}{l}\text { Appenzell } \\
\text { Outerrhodes } \\
\text { and Zug }\end{array}$ \\
\hline+ & or & \\
\hline outsourc*COOP & $\begin{array}{l}\text { where alcohol policy tasks are not outsourced } \\
\text { and which are open to horizontal and vertical } \\
\text { cooperation }\end{array}$ & $\begin{array}{l}\text { Basel City and } \\
\text { Geneva }\end{array}$ \\
\hline+ & or & \\
\hline decentral*PROMVETO & $\begin{array}{l}\text { with a centralized responsibility for alcohol } \\
\text { policy within the administration and with } \\
\text { strong promoters of health-oriented alcohol } \\
\text { policy as well as weak veto players }\end{array}$ & Bern \\
\hline+ & or & \\
\hline decentral*PROBLEM & $\begin{array}{l}\text { with a centralized responsibility for alcohol } \\
\text { policy within the administration and with } \\
\text { problem pressure }\end{array}$ & $\begin{array}{c}\text { Jura and } \\
\text { Valais }\end{array}$ \\
\hline+ & or & \\
\hline DECENTRAL*COORD*DEPINV*coop & $\begin{array}{l}\text { with decentralized responsibilities for alcohol } \\
\text { policy within the administration and with a } \\
\text { high level of inner-administrative } \\
\text { coordination and more than three } \\
\text { departments involved and which are not } \\
\text { open to horizontal and vertical cooperation }\end{array}$ & $\begin{array}{l}\text { Vaud and } \\
\text { Zurich }\end{array}$ \\
\hline
\end{tabular}

The five solutions can be divided into three groups of cantons displaying complementary or even contradictory settings that both foster program adoption.

The first group encompassing the first two solutions contains cantons in which policy responsibilities are centralized and the respective tasks and services are provided and produced by the respective public authorities. Together with the willingness to cooperate with other cantons and the federal level, the various constellations of these three idiosyncrasies as we can find them in the cantons of Appenzell Outerhodes, Basel City, Geneva and Zug provide a favorable setting for program adoption. We label this group the "cooperative bureaucracy" as the two features of centralization and direct provision of public goods are characteristics of the classic administrative model coupled with the will to cooperate.

The second group contains the two combinations with a centralized administration and either strong vested interests in favor of alcohol control or high alcohol consumption. This coupling of centralization with either the politics stream or the problem stream is found in Bern, Jura, and Valais. We call this group "pressure or problem".

The third group, then, comprises the two cantons of Zurich and Vaud where we find a completely different constellation of conditions fostering program adoption. Unlike in the other two groups, this constellation combines decentralized structures with many departments involved coupled with a strong inner administrative coordination, but reluctant to cooperate with other cantons or the central state. Whereas in the first group, consolidated and cooperative structures endorse program adoption, we encounter here quite the opposite, namely fragmented structures and reluctance to cooperate coupled with strong coordination. We label this solution "fragmented autarchy". Apparently, program adoption in these cantons is advanced due to their domestic focus and decision-making takes place 
among the various agencies and not due to external exchange. This may be due to the fact that the two cantons in this group are very large and active and also have strong urban centers.

Conditional settings for non-adoption of policy programs

In order to analyze the absence of program adoption, we again include all nine conditions (LEFTDEP + PROMVETO + PROBLEM + DECENTR + OUTSOU + SPE-

CIAL + COORD + DEPINV + COOP). csQCA identifies three combinations of conditions which this time hinder alcohol policy program adoption.

\begin{tabular}{|c|c|c|}
\hline progadopt: & $\begin{array}{l}\text { Program adoption is not } \\
\text { encountered in cantons }\end{array}$ & Cases \\
\hline promveto*problem*OUTSOURC & $\begin{array}{l}\text { with weak promoters of health- } \\
\text { oriented alcohol policy as well as } \\
\text { strong veto players and with little } \\
\text { problem pressure in which alcohol } \\
\text { policy tasks are mostly } \\
\text { outsourced. }\end{array}$ & $\begin{array}{l}\text { Appenzell Innerrhodes, } \\
\text { Argovia, Glarus, Saint } \\
\text { Gall, Schwyz and Uri }\end{array}$ \\
\hline+ & or & \\
\hline DECENTRAL*coord*coop & $\begin{array}{l}\text { with decentralized responsibilities } \\
\text { for alcohol policy and with a low } \\
\text { level of inner-administrative } \\
\text { coordination and which are not } \\
\text { open to horizontal and vertical } \\
\text { cooperation }\end{array}$ & $\begin{array}{l}\text { Fribourg, Grisons, Glarus, } \\
\text { Obwald, Nidwald, } \\
\text { Schaffhausen, Solothurn, } \\
\text { and Thurgovia }\end{array}$ \\
\hline+ & or & \\
\hline DECENTRAL*OUTSOURC*COOP & $\begin{array}{l}\text { with decentralized responsibilities } \\
\text { for alcohol policy and in which } \\
\text { alcohol policy tasks are mostly } \\
\text { outsourced and which are open to } \\
\text { horizontal and vertical } \\
\text { cooperation }\end{array}$ & $\begin{array}{l}\text { Basel Land, Neuchâtel and } \\
\text { Ticino }\end{array}$ \\
\hline
\end{tabular}

We can group these combinations of conditions in two more general situational settings, namely one politically marked constellation and one organizational setting both of which do not lead to program adoption.

The first group encompasses the first solution where both the politics stream and the problem stream play a role. These cantons display a political setting hindering program adoption as we find a lack of societal promoters for health-oriented alcohol policy as well as strong veto players in this second solution. This condition is combined with little problem pressure regarding alcohol consumption and an administrative organization that does not produce the respective services itself but outsources the respective tasks. In this constellation found in the cantons of Appenzell Innerrhodes, Argovia, Glarus, Saint Gall, Schwyz and Uri, there is neither a problem stream in form of an obvious need nor political will for further activities against harmful alcohol consumption. Correspondingly, we label these cantons as the "neither need nor will" group.

The second group comprises the last two constellations in which we find merely organizational conditions in combinations that to a certain degree are opposed to the first group of constellations displaying program adoption. The common feature of the two 
constellations is the decentralized structures in charge which seem to prevent alcohol policy program adoption in two situations, namely first in combination with both no coordination and no will to cooperate externally as in Fribourg, Grisons, Glarus, Obwald, Nidwald, Schaffhausen, Solothurn, and Thurgovia, and second, in combination with both outsourcing and cooperation as in Basel Land, Ticino, and Neuchâtel. Apparently, decentralization prevents program adoption in both externally oriented and domestically oriented settings. Consequently, we label this group the "decentralized setting".

\section{Sorting through the garbage can}

Our comparative study leads to a number of insights of both theoretical and substantive nature. First, the theoretical argument that the garbage can model profits from the inclusion of institutional factors in order to fully reflect organizational reality finds clear support in our study. Given that both solution stream and policy window were stable, the csQCA yields five combinations that lead to program adoption three of which consist only of characteristics of the organizational structure. Likewise, two of the three combinations of factors that did not lead to program adoption also only include organizational factors. In contrast, the presence or absence of policy entrepreneurs only played a role in one term of each respective solution. The inclusion of institutional elements thus helped us to shed light on the question of "why some decisions tend to become garbage cans and others do not" (Zahariadis 2007: 84). This finding is a strong argument for a more institutionalistic approach in garbage can applications that may rely on the neo-institutionalist writings of two of the inventors of the garbage can model (March and Olsen 1984, 1989).

Second, the study supports the contention of independent streams. Especially, the garbage can feature that the problem stream can be regarded as independent from the solution stream has led to irritation by critics (Bendor et al. 2001: 172). Cohen et al. (1972: 16) state: "Although decision-making is thought of as a process for solving problems that is often not what happens. Problems are worked upon in the context of some choice, but choices are made only when the shifting combinations of problems, solutions, and decision-makers happen to make action possible." Our study supports this assertion. In fact, only in one of the different configurations of conditions for program adoption does the problem stream pop up. And again, only in one constellation that did not lead to program adoption does the absence of problem pressure play a role. In both solutions, the effect was in the direction we expected based on theory. In most our cases, however, solutions are in fact decided without linear recurrence to problems.

Third, the politics stream in our study matters both in a combination fostering and in one preventing alcohol program adoption. In both constellations, however, it is the vested interests and not party politics that play a role. Based on our cases, this result is due to the contacts between health organizations and the responsible administration within epistemic policy communities. These contacts are closer than the ones between the administration and party politics. This is in line with our understanding of policy programs as the concrete operationalization of an existing policy in order to implement it (Pressman and Wildavsky 1974). Consequently, a policy program necessarily is in line with the policy it stems from. Otherwise, the definition would not make sense. While the policy is decided by party politics in legislature and executive, however, organized interests in favor of active health policy may well take actions to get the administrative actors in gear to set up a concrete policy program. As for non adoption, it makes sense for political opponents of the policy in place to impede program adoption to prevent the policy from being implemented. The 
political logic of program adoption thus differs from the ones of policy change and instrument choice as it is vested interests rather than party politics that are important and the concern is not the policy as such but primarily its implementation.

Finally, while the study provided different and partly inconsistent explanations of program adoption, it gives various hints that alcohol program adoption is more likely to take place in classic bureaucratic structures than in decentralized and limited government structures. On the one hand side, we found program adoption in either cooperative bureaucracy where tasks were not outsourced, in centralized structures coupled with the politics or the problem stream, or in well coordinated autarchic administrations. All of these settings display features of the classic bureaucratic model (Goodsell 1994; Olsen 2001). On the other hand side, program adoption did not take place in cantons that outsource their alcohol policy tasks or are organized in a decentralized manner or both. While the actual solutions of course are more complex than this, the overall picture implies that classic bureaucratic structures are better suited to put policies into practice than limited government.

In sum, our findings make a strong argument for Padgett's (1980: 583-584) point that the organized anarchy paradigm can be usefully applied to "fairly traditional and bureaucratic structure." What is more, we have shown that garbage can decision-making can be better explained and understood when its institutional setting is taken into account.

\section{Conclusion}

In this study, we have investigated the causes for policy program adoption. Policy programs are operationalizations of policies and program adoption unlike policy change or policy instrument choice therefore can be understood as administrative decisions rather than political ones. We complemented the garbage can model of organizational choice with institutional elements of organizational structure. This has proved to be an appropriate scheme to understand the causes for program adoption. In the systematic comparison of alcohol policy program adoption in the Swiss cantons employing csQCA, we identify different combinations of factors that encouraged program adoption in ten cantons and another set of different conjunctions of features that prevented program adoption in sixteen cantons. As for the cantons that adopted new policy programs, we have grouped the five identified constellations in three sets of cantons which we label as "cooperative bureaucracy", "pressure or problem", and "fragmented autarchy" according to the common distinctive features of these groups. As for the absence of program adoption, the three combinations of conditions can be grouped in two sets we label as "neither need nor will" and "decentralized setting". The labels make it clear that both adoption and non-adoption of policy programs take place in very different settings. The analysis provides a realistic image of the polymorphic and complex realities of policy dynamics as it shows that the cantonal decision to adopt health-oriented alcohol policy programs cannot be explained monocausally. Additionally, our study confirms the assumption of asymmetric causality in that the absence of factors explaining program adoption does not equal non-occurrence of program adoption. With recourse to theory, the configurative approach helped to shed light on the question of when various streams meet and lead to decisions. The structural factors of administrative organization turn out to be decisive in this respect. A more institutionalistic form of the garbage can model is thus in order.

The present study has its limitations which is why further lines of research ought to be discussed here. As for one, our study is limited to a single policy. This makes sense in 
terms of a controlled comparative research design. However, further research may profit from cross-sectoral comparisons in order to find policy-specific patterns of program adoption. Second, the two contradicting cases in our sample point to insufficient theoretical modelling and qualitative further investigation will help to find relevant causes missing in this study. Such research may sensibly investigate into the process aspect of garbage can decisions and their historical background as proposed by Heimer and Stinchcombe (1999). Finally, our study reveals classic bureaucratic structures to be more apt for turning policies into programs than limited government structures. This finding fully concurs with Olsen's (2006: 2) cue "that for those interested in how contemporary public administration is organized, functions, and changes, it is worthwhile to reconsider and rediscover bureaucracy as an administrative form, an analytical concept and a set of ideas and observation about public administration and formally organized institutions." The finding also has a strong normative aspect. Both Padgett (1980) and Hood (1999) stress the prescriptive side of the garbage can model. "In a world of corporate mission statements full of businessschool clichés about coherent strategy and tight-ship processing, the model stresses the inescapable role of happenstance, $\mathrm{x}$-factors and chance connections in complex institutions" (Hood 1999: 60). Whereas Padgett (1980) finds that in hierarchical settings, heads of hierarchies should delegate decisions to lower levels rather than engage in active tactical maneuvering, our results are more diverse due to the different organizational settings we found and which are not always hierarchical. Further research may work on the managerial implications of the model in different institutional settings. As indicated by Padgett (1980: 584), "given unorthodox theories, it is perhaps not surprising that resultant managerial recommendations are similarly unorthodox." Further study thus might lead to public management prescriptions based less on textbook recipes and more appropriate for a complex organizational reality within the boundaries of bureaucratic structures.

\section{References}

Baumberg, B., \& Anderson, P. (2008). Health, alcohol and EU law: Understanding the impact of European single market law on alcohol policies. European Journal of Public Health, 18(4), 392-398.

Bemelmans-Videc, M.-L., Rist, R. C., \& Vedung, E. (Eds.). (1998). Carrots, sticks, and sermons: Policy instruments and their evaluation. New Brunswick, NJ: Transaction Publishers.

Bendor, J., Moe, T. M., \& Shotts, K. W. (2001). Recycling the garbage can: An assessment of the research program. American Political Science Review, 95, 169-190.

Berg-Schlosser, D., De Meur, G., Rihoux, B., \& Ragin, C. (2009). Qualitative comparative analysis (QCA) as an approach. In B. Rihoux \& C. Ragin (Eds.), Configurational comparative methods. Qualitative comparative analysis (QCA) and related techniques (pp. 1-18). London: Sage.

Cattacin, S., \& Lucas, B. (1999). Autorégulation, intervention étatique, mise en réseau: Les transformations de l'État social en Europe (les cas du VIH/sida, de l'abus d'alcool et des drogues illégales). Revue française de science politique, 49, 379-398.

Cohen, M. D., March, J. G., \& Olsen, J. P. (1972). A garbage can model of organizational choice. Administrative Science Quarterly, 17, 1-25.

Feiock, R. C., \& West, J. P. (1993). Testing competing explanations for policy adoption: Municipal solid waste recycling programs. Political Research Quarterly, 46, 399-419.

Goodsell, C. T. (1994). The case for bureaucracy. A public administration polemic. Chatham, NJ: Chatham House Publishers.

Hall, P. A. (1993). Policy paradigms, social learning, and the state: The case of economic policymaking in Britain. Comparative Politics, 25, 275-296.

Heimer, C. A., \& Stinchcombe, A. L. (1999). Remodeling the garbage can: Implications of the origins of items in decision streams. In M. Egeberg \& P. Laegreid (Eds.), Organizing Political Institutions. Essays for Johan P. Olsen (pp. 25-57). Oslo: Scandinavian University Press. 
Hibbs, D. A. (1977). Political parties and macroeconomic policy. American Political Science Review, 71, 1467-1487.

Hood, C. (1999). The garbage can model of organization: Describing a condition or a prescriptive design principle? In M. Egeberg \& P. Laegreid (Eds.), Organizing Political Institutions. Essays for Johan P. Olsen (pp. 59-78). Oslo: Scandinavian University Press.

Jeanrenaud, C. (2003). Die sozialen Kosten des Alkoholmissbrauchs in der Schweiz. Neuenburg: Institut de recherches économiques et régionales (IRER).

Kaufmann, V., \& Sager, F. (2006). The coordination of local policies for urban development and public transportation in four Swiss cities. Journal of Urban Affairs, 28, 353-374.

Kingdon, J. W. (1984). Agendas, alternatives and public policy. New York: Harper Collins.

Lodge, M. (2003). Institutional choice and policy transfer: Reforming British and German Railway regulation. Governance, 16, 159-178.

March, J. G., \& Olsen, J. P. (1984). The new institutionalism: Organizational factors in political life. American Political Science Review, 73, 734-749.

March, J. G., \& Olsen, J. P. (1989). Rediscovering institutions: The organizational basis of politics. New York: Free Press.

Matishoff, D. C. (2008). The adoption of state climate change policies and renewable portfolio standards: Regional diffusion or internal determinants. Review of Policy Research, 25, 527-546.

Meier, K. J. (1994). The politics of sin. Drugs, alcohol, and public policy. Armonk/London: M.E.Sharpe.

Nowak, T. (2010). Of garbage cans and rulings: Judgments of the European court of justice in the EU legislative process. West European Politics, 33, 753-769.

O'Toole, L. J., Jr, \& Meier, K. J. (1999). Modelling the impact of public management: Implications of structural context. Journal of Public Administration Research and Theory, 9, 505-526.

Olsen, J. P. (2001). Garbage cans, new institutionalism, and the study of politics. American Political Science Review, 95, 191-198.

Olsen, J. P. (2006). Maybe it is time to rediscover bureaucracy. Journal of Public Administration Research and Theory, 16(1), 1-24.

Padgett, J. F. (1980). Managing garbage can hierarchies. Administrative Science Quarterly, 25, 583-604.

Perrow, C. (1977). Review of ambiguity and choice in organizations. Contemporary Sociology, 6, $294-298$.

Pressman, J. L., \& Wildavsky, A. B. (1974). Implementation. How great Expectations in Washington are dashed in Oakland. Berkeley: University of California Press.

Ragin, C. (1987). The comparative method. Moving beyond qualitative and quantitative strategies. Berkeley: University of California Press.

Rehm, J., et al. (1999). Assessment methods for alcohol consumption, prevalence of high risk drinking and harm: A sensitivity analysis. International Journal of Epidemiology, 28, 219-224.

Rehm, J., et al. (2003). The relationship of average volume of alcohol consumption and patterns of drinking to burden of disease: An overview. Addiction, 98(9), 1209-1228.

Rogers, E. M. (1995). Diffusion of innovations. New York: The Free Press.

Sabatier, P. A., \& Jenkins-Smith, H. C. (1999). The advocacy coalition framework: An assessment. In P. A. Sabatier (Ed.), Theories of the policy process (pp. 117-168). Westview: Boulder.

Sager, F. (2003). Kompensationsmöglichkeiten föderaler Vollzugsdefizite. Das Beispiel der kantonalen Alkoholpräventionspolitiken. Swiss Political Science Review, 9, 309-333.

Sager, F. (2005). Metropolitan institutions and policy coordination: The integration of land use and transport policies in Swiss urban areas. Governance, 18(2), 227-256.

Sager, F. (2007). Habermas' models of decisionism, technocracy, and pragmatism in times of governance. Public Administration, 85, 429-447.

Sager, F. (2009). Governance and coercion. Political Studies, 57, 537-558.

Sager, F., \& Schläpfer, M. (2004). Alkoholpolitische Kantonsprofile. Bern: Study for the Swiss Alcohol Board and the Federal Office of Public Health.

Sager, F., \& Vatter, A. (2000). Strukturen und Strategien der Kantone in der Alkoholpräventionspolitik. Bern: Study for the Swiss Foundation for Alcohol Research.

Schneider, A., \& Ingram, H. (1993). Social construction of target populations: Implications for politics and policy. American Political Science Review, 87(2), 334-347.

Schneider, C. Q., \& Wagemann, C. (2012). Set-theoretic methods for the social sciences. A guide to qualitative comparative analysis. Cambridge: CUP.

Tsebelis, G. (2002). Veto players: How political institutions work. Princeton, NJ: Princeton University Press.

Ugland, T. (2003). Adaptation and integration through policy re-categorization. Journal of Public Policy, 23(2), 157-170.

Varone, F., Rothmayr, C., \& Montpetit, E. (2006). Regulating biomedicine in Europe and North America: A qualitative comparative analysis. European Journal of Political Research, 45, 317-343. 
Vatter, A., \& Rüefli, C. (2003). Do political factors matter for health care expenditure? A comparative study of Swiss cantons. Journal of Public Policy, 23, 301-323.

Yamasaki, S., \& Rihoux, B. (2009). A commented review of applications. In B. Rihoux \& C. Ragin (Eds.), Configurational comparative methods. Qualitative comparative analysis $(Q C A)$ and related techniques (pp. 123-146). London: Sage.

Zahariadis, N. (2007). The multiple streams framework: Structure, limitation, prospects. In P. A. Sabatier (Ed.), Theories of the policy process (2nd ed., pp. 65-92). Boulder: Westview.

Zucker, L. G. (1983). Organizations as institutions. In S. B. Bachrach (Ed.), Research in the sociology of organizations (pp. 1-42). Greenwich, CT: JAI Press. 